\title{
Behavior and Cost of Travel of Thai Travelers Using Low-Cost Airlines in Bangkok, Thailand
}

\author{
Wanrudee Suksanguan[a] \\ Nakamol Chansom[b]
}

\begin{abstract}
This research aimed to: (1) study the travel behavior of Don Mueang Airport service users (2) investigate the types of travelling expenses and (3) examine the relationships between purposes of travel and modes of travel. The population and the sample included 400 Don Mueang Airport service users. The research instrument was a questionnaire. The statistics included frequency, percentage and Pearson Chi-Square. The research findings are as follows. (1) The travelers had travel frequency of not more than 5 times a year were at 64.7 percent, traveled to Don Mueang Airport by taxis were at 55.3 percent, travelers traveled 1- 2 persons were at 57.4 and travelers arrived at Don Mueang Airport 2-3 hours before flight time was at the rate of 68.1 percent. The purposes of travel were for vacation and for work, representing 42.3 percent and 28.1 percent respectively. (2) The top three expenses traveler spent on were for food and beverage, for accommodation and for travelling, representing 25.3 percent, 24.5 percent and 24.2 percent respectively. (3) The purposes of travel and modes of travel were significantly correlated at 0.020 .
\end{abstract}

Keywords - Travel behavior, cost of travel, low-cost airlines

\section{Introduction}

Nowadays, low-cost airlines are widely popular because they offer airfares which are 40-50 percent lower than airfares of economy class offered by large airlines. This is because low-cost airlines reduce several costs by, for example, offering only economy class to increase seats, using secondary airports that require less airport fees, using only one aircraft model to reduce maintenance cost, no food and beverage served on board and using e-ticketing to directly sell tickets to customers to reduce commission fee. There were 3 low-cost airlines that were launched in Thai aviation industry in 2003. Nowadays, there are 37 low-cost airlines [1]. The well-known low-cost airlines in Thailand that have more than half of market share are Thai smile, Thai Airasia, Nok Air and Thai Lion air. Similarly, the center of low-cost airlines is Don Mueang Airport which is a secondary airport. The strategy of Airports of Thailand Public Company Limited assigns Don Mueang Airport as a service center for low-cost airlines to offer rapid, convenient and simple services. At present, Don Mueang Airport can support 30 million passengers per year. However, in 2016 and 2017 the passengers using the airport climbed to 35.2 and 37.18 million respectively [2] which is higher than

[a] Faculty of Accounting, Rangsit University

Country : Thailand

[b] Faculty of Business Administration, Rangsit University Country : Thailand the carrying capacity of the airport. As a result, the airport encountered service user density that exceeds the carrying capacity of the airport. Therefore, Don Mueang Airport has an improvement plan as follow: (1) to expand the airport and it is expected to complete in 2022 to support 40-50 flights per hours and support 40 million passengers per year: (2) to construct an elevated rapid transit system or a free automatic passenger transit connected between parking lots and passenger buildings and other areas in the airport and connected to Red Line suburban railway system of State Railway of Thailand and: (3) the Minister of Transport proposed a Bangkok-Rayong High-Speed Rail Link aiming to connect 3 airports including Don Mueang Airport, Suvarnabhumi Airport and U-Tapao Airport as well as Airport Rail Link. In addition, in 2018 Airports of Thailand Public Company Limited has a plan to increase commercial space by opening an auction for commercial space at Don Mueang International Airport [3] (Thairath Online, June 28, 2018).

As mentioned above, Don Mueang Airport is about to expand in the future because low-cost airlines have been continually growing, resulting in driving Thai tourism [4] and tourism business which spearhead Thai economy. According to surveys by National Statistical Office and Tourism Authority of Thailand in 2016 indicated that the average expense spent on travelling per person was 3,984 baht [5] which is not high. This is consistent with travel behavior, focusing on economical modes that are widely popular among travelers. That is, travelers select airlines that mainly focus more on travel and that do not provide excessive facilities so that they can offer low airfares. As a result, travelers select to travel with low-cost airlines and come to Don Mueang International Airport. The interesting aspect is travel behavior including modes of travel to the airport, activities travelers do while waiting for their flights, purposes of travel, travel frequency and a number of travelers. In addition, another interesting aspect is that how a reduction of cost of travel through using low-cost airlines affects other expenses and which expense has the highest proportion. The answers to these questions enable a planners to know that weather lowcost airlines attract travelers or not and to enable Don Mueang Airport know that how facilities, products and services shall be provided to meet behavior of Don Mueang Airport service users. Significantly, Tourism Authority of Thailand can use the data for promoting tourism activities. 


\section{Research objectives}

1. To study the travel behavior of Don Mueang Airport service users.

2. To investigate the types of travelling expenses.

3. To examine the relationships between purposes of travel and modes of travel.

\section{Research hypotheses}

Purposes of travel are correlated with modes of travel.

\section{Conceptual framework}

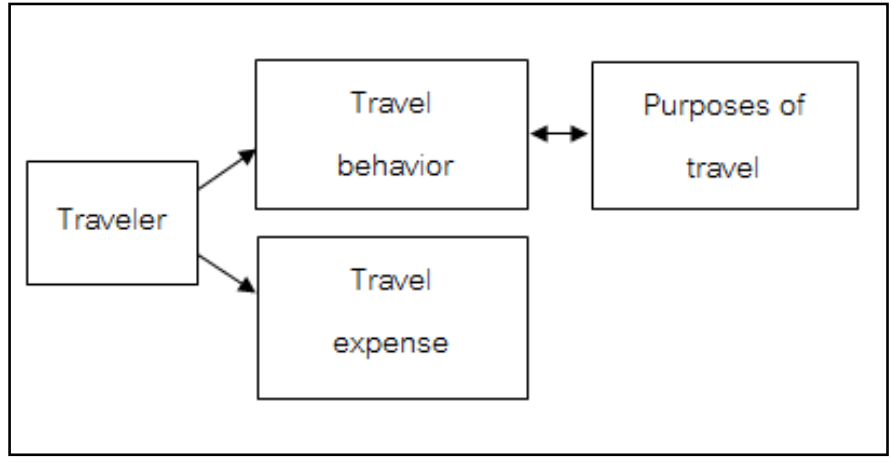

\section{Methodology}

This research aimed to study travel behavior and cost of travel of low-cost airlines users at Don Mueang Airport. The study is Quantitative Research using an in-depth interview to construct a questionnaire. The constructed questionnaire was applied to collect data. The detailed study is as follows.

The population and the sample included service users at Don Mueang Airport passenger terminal.

The scope of the study included service users at Don Mueang Airport passenger terminal during March 15-31, 2017.

To determine the sample size of service users at Don Mueang Airport passenger terminal, Yamane's table (1993) at the reliability of 95 percent was applied. The sample included 400 people selected by Accidental Sampling. The sample was given a questionnaire while they were at a passenger terminal.

Research process is as follows.

Step 1 Conducting an in-depth interview with 20 users at a at Don Mueang Airport passenger terminal.

Step 2 Constructing a questionnaire.

Step 3 Conducting a pretest for the constructed questionnaire.

Step 4 Using the constructed questionnaire in the study.
The research instruments were an in-depth interview form and a questionnaire.

Statistics applied in the study were frequency, percentage and Pearson Chi-Square.

\section{Results}

The findings on travel behavior and cost of travel of Don Mueang users are as follows.

1. General information showed that :

- The respondents were males, representing 32.4 percent and females, representing 67.6 percent.

- The respondents aged below 25 years old were at 39.1 percent, $25-30$ years old were at 22.3 percent, 31-40 years old were at 15.1 percent, 51-60 years old were at 8.4 percent and 61 years old and above were at 1.5 percent.

- The respondents who had lower than bachelor's degrees were at 26.3 percent, had diplomas were at 4.7 , had bachelor's degrees were at 58.3 and had higher than bachelor's degrees were at 10.7 percent.

- The respondents who were students were at 29.2 percent, employees were at 27.2 percent, government officials/state enterprise employees were at 19.8 percent, business owners were at 12.1 percent, housewives were at 3.5 percent and others were at 8.2 percent.

- The respondents whose income was lower than 15,000 baht were at 41.4 percent, 15,000 - 25,000 baht were at 29.9 percent, 25,001 - 35,000 baht were at 9 percent, 35,001 - 50,000 baht were at 11.0 percent, 50,001 - 100,000 were at 6.7 percent and 100,000 and above were at 2 percent.

2. The reliability of the questionnaire was tested. 30 sets of questionnaires were given to Don Mueang Airport service users and Cronbach's alpha coefficient was identified. The reliability of the questionnaire was at 0.877 , considering as high value. Therefore, the research used the constructed questionnaire with the actual sample.

3. Travel behavior of Don Mueang Airport service users was studied according to the following aspects.

- Travel frequency: Within one year, more than half of travelers who used Don Mueang Airport 5 times or less was at 64.7 percent, travelers who used Don Mueang Airport more than 10 times were at 18.8 percent and travelers who used Don Mueang Airport 6-10 times were at 16.5 percent. 
Proc. of the Sixth Intl. Conf. Advances in Social Science, Economics and Management Study - SEM 2018 Copyright (C) Institute of Research Engineers and Doctors, USA .All rights reserved.

ISBN: 978-1-63248-151-1 doi: 10.15224/978-1-63248-151-1-52

TABLE 1 TRAVEL FREQUENCY

\begin{tabular}{|l|r|r|}
\hline & Frequency & \multicolumn{1}{c|}{ Percent } \\
\hline 1-5 times per year & 258 & 64.7 \\
\hline 6-10 times per year & 66 & 16.5 \\
\hline More than 10 times per year & 75 & 18.8 \\
\hline Total & 399 & 100 \\
\hline
\end{tabular}

- Mode of travel: More than half of or 55.3 percent of Don Mueang Airport service users used taxis. The rest of them had someone drop them off/pick them up, used public buses, drove their cars, used buses provided by tour groups and others, representing 16.6 percent, 15.6 percent, 10.4 percent, 1.25 percent and 0.7 percent respectively.

TABLE 2 MODE OF TRAVEL

\begin{tabular}{|l|r|r|}
\hline & Frequency & \multicolumn{1}{c|}{ Percent } \\
\hline Public buses & 63 & 15.6 \\
\hline Taxi & 223 & 55.3 \\
\hline Having Someone to Pick up & 67 & 16.6 \\
\hline Drive yourself & 42 & 10.4 \\
\hline Provided by tour groups & 5 & 1.2 \\
\hline Other & 3 & 0.7 \\
\hline Total & 403 & 100 \\
\hline
\end{tabular}

- A number of fellow travelers: More than half of travelers or 57.4 percent traveled 1-2 persons. The rest of them traveled 3-4 person and 5 person and above, representing 23.4 percent and 19.2 percent respectively.

\section{TABLE 3 NUMBER OF FELLOW TRAVELERS}

\begin{tabular}{|c|r|r|}
\hline & Frequency & \multicolumn{1}{c|}{ Percent } \\
\hline $1-2$ & 230 & 57.4 \\
\hline $3-4$ & 94 & 23.4 \\
\hline 5 up & 77 & 19.2 \\
\hline Total & 401 & 100 \\
\hline
\end{tabular}

- Arrival period at the airport before flight time: Travelers who arrived at the airport 2-3 hours before their flights were at 68.1 percent. The rest of them arrived at the airport 1 hour, 4 hours, 5 hours and 5 hours and up, representing 19.3 percent, 7.8 percent, 2.5 percent and 2.5 percent respectively.
TABLE 4 ARRIVAL PERIOD BEFORE FLIGHT TIME

\begin{tabular}{|c|r|r|}
\hline Hours & Frequency & \multicolumn{1}{c|}{ Percent } \\
\hline 1 & 77 & 19.3 \\
\hline 2 & 181 & 45.3 \\
\hline 3 & 91 & 22.8 \\
\hline 4 & 31 & 7.8 \\
\hline 5 & 10 & 2.5 \\
\hline 5 and up & 10 & 2.5 \\
\hline Total & 400 & 100 \\
\hline
\end{tabular}

4. Purposes of travel: More than half of Don Mueang Airport service users traveled for vacation and for work, representing 42.3 percent and 28.1 percent respectively. The rest of them traveled for returning their hometowns, for study, for visiting relatives and others, representing 13.9 percent, 9.0 percent, 5.0 percent and 1.7 percent respectively.

TABLE 5 THE PURPOSE OF THE TRIP
\begin{tabular}{|c|c|c|}
\hline & Frequency & Percent \\
\hline Traveled & 170 & 42.3 \\
\hline Work & 113 & 28.1 \\
\hline For study & 36 & 9 \\
\hline Visit & 20 & 5 \\
\hline Back home & 56 & 13.9 \\
\hline Other & 7 & 1.7 \\
\hline Total & 402 & 100 \\
\hline
\end{tabular}

5. Cost of travel: Cost of travel mostly spent by travelers included food and beverage, accommodation and travel fares, representing 25.3 percent, 24.5 percent and 24.2 percent respectively. The rest of them included service fees, miscellaneous expenses, souvenirs and entertainment, representing 9.5 percent, 8.2 percent, 4.4 percent and 3.9 percent respectively.

TABLE 6 COST OF TRAVEL

\begin{tabular}{|l|r|r|}
\hline & Frequency & \multicolumn{1}{|c|}{ Percent } \\
\hline Accommodation & 95 & $\mathbf{2 4 . 5}$ \\
\hline $\begin{array}{l}\text { Food and } \\
\text { beverage }\end{array}$ & $\mathbf{9 8}$ & $\mathbf{2 5 . 3}$ \\
\hline Travel & $\mathbf{9 4}$ & $\mathbf{2 4 . 2}$ \\
\hline Entertainment & $\mathbf{1 5}$ & $\mathbf{3 . 9}$ \\
\hline Souvenirs & $\mathbf{1 7}$ & $\mathbf{4 . 4}$ \\
\hline Service fees & $\mathbf{3 7}$ & $\mathbf{9 . 5}$ \\
\hline Other & $\mathbf{3 2}$ & $\mathbf{8 . 2}$ \\
\hline Total & $\mathbf{3 8 8}$ & $\mathbf{1 0 0}$ \\
\hline
\end{tabular}




\section{Hypothesis testing}

Purposes of travel are correlated with modes of travel. The results of hypothesis testing are as follows.

TABLE 7 HYPOTHESIS TESTING SHOWING THAT PURPOSES OF TRAVEL ARE CORRELATED WITH MODES OF TRAVEL.

\begin{tabular}{|l|r|r|r|}
\hline & \multicolumn{1}{|c|}{ Calue } & \multicolumn{1}{|c|}{ Chi-Square Tests } & \multicolumn{1}{c|}{$\begin{array}{c}\text { Asymp. Sig. } \\
\text { (2-sided) }\end{array}$} \\
\hline Pearson Chi-Square & $19.687 \mathrm{a}$ & 9 & .020 \\
Likelihood Ratio & 21.072 & 9 & .012 \\
Linear-by-Linear Association & 1.787 & 1 & .181 \\
N of Valid Cases & 402 & & \\
\hline
\end{tabular}

a. 1 cells (6.3 percent) have expected count less than 5 . The minimum expected count is 4.48 .

According to the above table, the researcher used Pearson ChiSquare to summarize the results. The Sig $=0.020<\mathrm{a}=0.05$. Therefore, it can be summarized that the purposes of travel are correlated with modes of travel at a statistical significance of 0.020 . The details are as follows.

TABLE 8 MODES OF TRAVEL CATEGORIZED BY PURPOSES OF TRAVEL

\begin{tabular}{|c|c|c|c|c|c|c|}
\hline \multicolumn{2}{|c|}{ Purposes of travel } & \multicolumn{4}{|c|}{ Modes of travel } & \multirow[t]{2}{*}{ Total } \\
\hline & & $\begin{array}{l}\text { Public } \\
\text { buses }\end{array}$ & Taxis & $\begin{array}{c}\text { Someone } \\
\text { drop them } \\
\text { off/pick } \\
\text { them up }\end{array}$ & $\begin{array}{c}\text { Buses } \\
\text { provided } \\
\text { by tour } \\
\text { groups }\end{array}$ & \\
\hline \multirow[b]{2}{*}{ Vacation } & Count & 30 & 81 & 34 & 25 & 170 \\
\hline & $\begin{array}{l}\text { percent } \\
\text { of Total }\end{array}$ & 7.5 & 20.1 & 8.5 & 6.2 & 42.3 \\
\hline \multirow[b]{2}{*}{ Work } & Count & 8 & 77 & 17 & 11 & 113 \\
\hline & $\begin{array}{l}\text { percent } \\
\text { of Total }\end{array}$ & 2.0 & 19.2 & 4.2 & 2.7 & 28.1 \\
\hline \multirow[b]{2}{*}{ Study } & Count & 7 & 18 & 8 & 3 & 36 \\
\hline & $\begin{array}{l}\text { percent } \\
\text { of Total }\end{array}$ & 1.7 & 4.5 & 2.0 & 0.7 & 9.0 \\
\hline \multirow{2}{*}{$\begin{array}{l}\text { Visit } \\
\text { relatives, } \\
\text { Return to } \\
\text { hometowns } \\
\text { and others }\end{array}$} & Count & 18 & 46 & 8 & 11 & 83 \\
\hline & $\begin{array}{l}\text { percent } \\
\text { of Total }\end{array}$ & 4.5 & 11.4 & 2.0 & 2.7 & 20.6 \\
\hline \multirow[b]{2}{*}{ Total } & Count & 63 & 222 & 67 & 50 & 402 \\
\hline & $\begin{array}{l}\text { percent } \\
\text { of Total }\end{array}$ & 15.7 & 55.2 & 16.7 & 12.4 & 100.0 \\
\hline
\end{tabular}

\section{Discussion}

\section{Travel behavior of Don Mueang Airport service users.}

Aspect 1 Travel frequency: More than half of the sample or 65 percent used Don Mueang Airport 5 times or less per year. This is consistent with a study of Sivadtra Pipatchaisiri, [6] which states that travelers used low-cost airlines 2-4 times a year. Similarly, during long holidays in Thailand, travelers used low-cost airlines about 5 times a year in January, April, May, October and December etc.

Aspect 2 Modes of travel: More than half of Don Mueang Airport service users or 55 percent used taxis. This is consistent with a study of Wanrudee Suksanguan, [7] which states that Don Mueang Airport encounters traffic congestion due to the lack of parking lots.

Aspect 3 A number of fellow travelers: More than half of travelers or 57 percent traveled only 1-2 persons. This is in line with studies of Sivadtra Pipatchaisiri, [6] and Kongkoon Tochaiwat, [8] which indicate that Thai travelers often traveled with a friend or a boyfriend/girlfriend.

Aspect 4 Arrival period at the airport before flight time: More than half of travelers or 68 percent arrived at the airport 2-3 hours before their flight time. This is in line with a study of Kongkoon Tochaiwat, [8] which states that travelers arrived at the airport 2-3 hours before boarding time to check in (for domestic and international flights) without rush.

Aspect 5 Purposes of travel: More than half of Don Mueang Airport service users traveled for vacation and for work, representing 42 percent and 28 percent respectively. This is in line with studies of Sivadtra Pipatchaisiri, [6] and Kongkoon Tochaiwat, [8] and the government policy that promotes tourism.

2. Types of cost of travel: Food and beverage was mostly spent on by travelers. This is consistent with a study of Wanrudee Suksanguan, [9] which indicates that traveler's flight waiting activity was eating. It was in the news published in January 2018, stating that Japanese media revealed that food prices at Don Mueang Airport was outrageously expensive. For example, a bottle of water was 40 baht. On January 29, 2018, the Office of the Ombudsman Thailand visited the airport and investigated the situation. It was found that the costs of some food were higher than the condition stated in the concession agreement of AOT, which allows prices to reach 20 percent higher than food sold in downtown department stores [10] due to its high rental fee. In addition, when arriving at the destinations it is necessary to consume 3 meals of food a day and Thai people enjoy eating delicious food. So, this has become a pricing criterion.

3 . The relationships between purposes of travel and modes of travel: It can be explained based on common sense that purposes of travel often involve belongings and travel frequency. Both of them determine modes of travel. For example, when compared to other purposes of travel, a traveler with lots of belongings often had less travel frequency. Therefore, a traveler who needed convenience often chose a taxi service. Other purposes of travel had different modes of travel according to a traveler's purpose. 


\section{Acknowledgment}

The researcher would like to extend sincere thanks to the President of Don Mueang Airport for granting permission for distributing questionnaires at Don Mueang Airport passenger terminal.

\section{References}

[1] Nitinai Sirisamuttakarn, "129 Million Passengers at 6 AOT Airports," Voice new. Retrieved on January 18, 2018 from www.voicetv.co.th , 2017, 3 November.

[2] Sutherawat Suwannawat, "Don Mueang Increases Carrying Capacity to Support Increasing Passengers," Prachachart Business. Retrieved on January 18, 2018. from https://www.prachachat.net, 2017, 17 November.

[3] Thairath Online (Electronic Version), “AOT's Plan to Open an Action of Commercial Space at Suvarnabhumi International Airport Don Mueang," Retrieved on 12 September 2017, from https://www.thairath.co.th/content/987031, 2017, 28 June.

[4] Kasikornthai, "Thai Tourism Market 2018," Kasikorn Research Center. Year $23^{\text {rd }}$ Vol. 2828, 2018.

[5] National Statistical Office, "Travel Behavior of Thai Travelers 2016," Retrieved on January 18, 2018, from http://www.ryt9.com/s/nso/2487655, 2016

[6] P.Sivadtra, "Influence Factors for Choosing Low-Cost Airline in Domestic Route of Thai Passengers," From http://resjournal.kku.ac.th, 2012, pp.158.

[7] S. wanrudee, "Study on the Use of Parking Spaces and Satisfaction of Thai People Using Don Mueang Airport in Bangkok Metropolis, Thailand," Research, 2017.

[8] T. Kongkoon and W. Burin, “ The Study of Flight Waiting Behavior of International Travelers,” Payap University Journal, Vol. 24(1) JanuaryJune 2014, PP. 93-108.

[9] S.wanrudee, and C. Piyarat, "Study on the Demands of Travelers and the Factors Influencing the Choosing Services at Don Mueang Airport, Bangkok Metropolis," Proceeding, Business Administration International Conference, $19^{\text {th }}$ December 2017,pp.166-167.

[10] Thairath, "Exorbitant Prices of Food at the Airports Continue," Retrieved on February 11, 2018.

About Author :

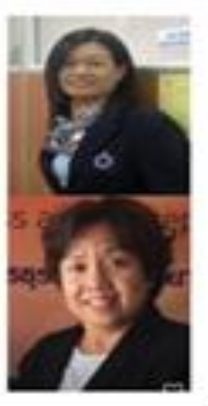

The travelers used Don Mueang Airport 5 times or less per year and travel by Taxi. Food and beverage was mostly spent on by travelers. The purposes of travel and modes of travel were significantly correlated at 0.020 